The Impact of Endowment Shocks on Payouts

by

Harvey S. Rosen, Princeton University

Alexander J. W. Sappington, Sappington \& Associates

Griswold Center for Economic Policy Studies

Working Paper No. 250, November 2016

Acknowledgements: We are grateful to Ken Redd of the National Association of College and University Business Officers for providing us with university endowment data and to Stephen Dimmock, Andrew Golden, Jane Gravelle, Jonathan Meer and David Sappington for useful suggestions. Financial support from Princeton's Griswold Center for Economic Policy Studies is gratefully acknowledged. 


\title{
The Impact of Endowment Shocks on Payouts
}

\begin{abstract}
Universities' endowment management practices have come under scrutiny by politicians and commentators who note that universities are tax-exempt, and do not want taxpayers subsidizing institutions only to have them accumulate wealth without advancing the public good. Defenders of university endowment policies argue that, to the contrary, they do not hoard endowment wealth for its own sake, but rather use their endowments to smooth spending over time. A critical question in this context is how the amounts that universities pay out from their endowments respond to shocks to the values of their endowments. Specifically, if universities reduce payouts in response to negative shocks more than they increase payouts in response to positive shocks, then their behavior is consistent with the notion that endowment managers care more about maintaining the value of their endowments than smoothing expenditures.

We investigate this issue using panel data on the payout behavior of over 700 universities during the period 1987 to 2009, and find that payouts are affected symmetrically by positive and negative shocks. While we make no attempt to argue that current payout policies are optimal for universities or for society, our findings do indicate that fears that universities are abusing their tax-exempt status by hoarding their endowments may be misplaced.
\end{abstract}

Harvey S. Rosen

Department of Economics

Princeton University

Princeton, NJ 08544

HSR@Princeton.edu
Alexander J. W. Sappington

Sappington \& Associates

4545 SW $97^{\text {th }}$ Terrace

Gainesville, FL 32608

alexandersappington@gmail.com 


\section{Introduction}

In recent decades, the endowments of wealthy universities have grown enormously - between 1993 and 2014, endowment balances grew from \$145 billion to \$516 billion in inflation-adjusted 2014 dollars (Sherlock, et al., 2015, p. 5). Conti-Brown (2011, p. 208) notes that during the 1990s, “Commentators ... extolled the genius of elite universities’ investment management departments,” but by 2007, the tone towards endowment accumulation had become considerably more negative. The most prominent reason for the shift is that the increase in endowment wealth was accompanied by substantial increases in tuition, which created concerns that universities were not using their wealth to make college more affordable. This issue received an enormous amount of press attention. For example, Wolf (2011. p. 596) notes that "between January and March 2008...the New York Times published almost fifteen pieces that discussed endowment, college tuition, or the growing wealth gap between institutions of higher education.” This concern made its way into the public policy arena, most prominently in 2008 when Senator Chuck Grassley and Representative Peter Welch organized a roundtable conference, tellingly entitled "Maximizing the Use of Endowment Funds and Making Higher Education More Affordable” (Sherlock et al., 2015, p. 1).

Public attention to this issue of endowment growth and utilization abated in 2008 due to the financial crisis, when endowments lost about 23 percent of their value (ContiBrown, 2011, p. 702). However, with the post-crisis recovery of the endowments came renewed criticism. Not atypical was the view that universities operate as if "preserving capital is a higher priority than preserving academic programs,” and treat their endowments as “hoarded treasure” (Coy 2009). Similarly, in 2011 Senator Grassley 
argued that lawmakers should "find ways to get educational institutions to help the people they're supposed to help instead of hoarding assets at taxpayer expense” (Grassley, 2011). ${ }^{1}$

Several policy changes have been proposed to reduce putative hoarding, including: requiring endowments to pay out some proportion of their total value annually, taxing endowments' investment earnings, and limiting the tax deduction on gifts to endowments (Sherlock et al., 2015, p. 1). While it is difficult to predict the direction that legislative proposals will take, Wolf (2011) argues that, given the tenor of recent discussions, a mandate to pay out specified amounts from the endowment each year is the most likely to become a formal legislative proposal. In May of 2016, for example, Representative Tom Reed of New York announced that he was drawing up legislation to require institutions with large endowments to channel at least 25 percent of their investment earnings to student aid. ${ }^{2}$

University leaders have vigorously rejected accusations of endowment hoarding, arguing that their endowment spending policies are designed to help smooth spending over time and preserve resources for future generations of students and faculty. They point out that the universities with the highest endowments provide generous financial support for low and middle-income families, and are not the institutions increasing tuition at the fastest rate (Wolf, 2011, p. 607). They argue further that a mandatory payout requirement would infringe on university independence, would not improve affordability for students, and would cause enormous legal and practical problems because substantial

\footnotetext{
1 Universities enjoy tax-exempt status, which is essentially a subsidy from the government designed to help universities pursue their mission.

2 See Seltzer (2016) for details.
} 
portions of endowments are restricted by donors to be used for specific purposes. ${ }^{3}$

Clearly, the issue of endowment hoarding is likely to be at the center of higher education debates in coming years.

Brown et al. (2014) convincingly argue that a natural way to assess the validity of the endowment hoarding accusation is to examine how universities respond to endowment shocks - exogenous, unexpected changes in the value of the endowment. If universities reduce payouts in response to negative shocks more than they increase payouts in response to positive shocks, then their behavior suggests that endowment managers care more about maintaining the value of their endowments than smoothing expenditures. Shocks, of course, are unobservable to the econometrician, who must make assumptions about how to infer them from available data. In this paper, we employ a fairly conventional approach to estimating shocks, although it has not been applied in this context before. We find that payouts are affected symmetrically by positive and negative shocks, a result that is inconsistent with endowment hoarding.

Section 2 provides some institutional background and reviews the relevant literature. Section 3 describes the data and presents summary statistics. In Section 4, we discuss our empirical framework. Section 5 presents and analyzes the results, and Section 6 concludes.

\section{Background}

Institutional setting. A university’s endowment is “an investment fund maintained for the benefit of the educational institution” (Sherlock et al., 2015, p.2).

3 Wolf (2011) provides a comprehensive summary of problems that could ensue from a mandatory payout regime. 
Endowments are legally separate entities from the universities they serve and external managers typically invest the endowment assets (Dimmock, 2012). In general, however, university trustees and administrators nevertheless maintain a high degree of control over how the endowment is managed and used, including the amount paid out to finance expenditures in any given year ${ }^{4}$ (Brown et al. 2014, p. 935).

Currently, no laws govern the amounts that universities must pay out from their endowments. This is not true for private foundations. ${ }^{5}$ Before 1969, there was a law that payouts for private foundations could be required if the size of the endowment became "unreasonable," with the presumption that what was unreasonable would be settled by the courts. In 1969, a new law established a minimum payout rate of 6 percent of assets, a figure that was adjusted to 5 percent of the foundation's net investment assets (regardless of its income for the year) in $1981 .{ }^{6}$ This figure is still in effect today. The key to understanding why a similar requirement has not been imposed on universities is that the 5 percent rule actually does not apply to all private foundations, only to so-called "nonoperating” foundations, defined as foundations that do not actively provide services. (Think of an institution that simply disburses grants.) In contrast, foundations that actively provide services are not subject to mandatory payout rules. The rationale for the distinction is that "operating” foundations may have substantial financial obligations to meet (such as paying a workforce), and a requirement to spend money from the endowment might impede its ability to meet such obligations. In short, the 5 percent rule is not applied to universities because they are viewed as operating foundations.

4 Brown et al. (2014, p. 935) note that "In more than three-quarters of endowments, the president, the CFO (who reports to the president), or both serve on the investment committee."

5 Conti-Brown (2011) provides a careful discussion of the history of the legal environment surrounding foundations.

6 See Joint Committee on Taxation (1981, pp. 366-368). 
Despite the absence of legal requirements, almost all universities claim to follow a (non-binding) "payout policy” or "spending rule," which is a formula based on observable metrics that determines the amount the university will take from the endowment to spend in the current year. Universities have adopted a variety of payout policies. As summarized in Brown and Tiu (2013), there are six categories. ${ }^{7}$ The first and simplest, which Cejnek et al. (2014) calls the "Merton rule," is to spend during each period a fixed percentage (known as the "policy payout rate") of the market value of the endowment at the beginning of that period. By definition, the policy payout rate is equal to the actual payout rate, because the starting value of the endowment is the only measure on which the payout value depends. For the second, and most common, category, the endowment pays out a fixed percentage (often 5 percent) of a moving average of endowment values (usually over the last 3 years). The policy payout rate is whatever the fixed percentage is, but the actual payout rate can vary depending on whether the value of the endowment has been growing or declining. When the endowment's average value over the past 3 years is lower than the value at the beginning of the current period, the actual payout rate is lower than the policy payout rate and vice versa. Because these rules reduce the variability in yearly payouts to the university, they are known as "smoothing rules” (Cejnek et al., 2013). Roughly 75 percent of all endowments claim to follow smoothing rules. Hybrid rules, the third category of payout policies, are similar to smoothing rules but generally combine them with another type of payout policy. ${ }^{8}$

\footnotetext{
Additional details can be found in Sedlacek and Jarvis (2010) and Murray (2011).
}

8 For example, one common hybrid rule is to set the payout value equal to one-half of 5 percent of the 3year moving endowment value average plus one-half of the previous year's payout, increased by the Higher Education Price Index level. 
According to Cejnek et al., (2014), almost 90 percent of universities employ one of these three types of spending rules. An important attribute they all share is that the payout value is based, either fully or in part, on the endowment value at the beginning of the year.

The remaining types of spending rules (roughly 10 percent of universities), which do not depend explicitly on endowment value, include: paying out a fixed percentage of the current yield on the investment of endowment assets, increasing the prior year's payout by a certain percentage (often dictated by the inflation rate), and simply determining the appropriate payout amount on a year-to-year basis.

The relative importance of payouts from endowments in university budgets varies substantially across types of institutions, if for no other reason than the enormous variation in the sizes of endowments - they range from zero to Harvard’s $\$ 36$ billion. According to The NACUBO-Commonfund Study of Endowments (2015, p. 52), in fiscal year 2015, on average 17 percent of the operating budgets of schools with endowments of $\$ 1$ billion or more were funded by endowments; the median value was 8.1 percent. On the other hand, for institutions with endowments in the \$51 million to \$100 million range, only 8.3 percent of operating budgets were generated by endowments on average, with a median of 3.0 percent. In public research institutions, whose endowments are relatively small, revenues from endowments accounted for only about 6 percent of operating revenues in 2010; for the more richly endowed private research institutions, the comparable figure was about 30 percent. ${ }^{9}$ Due to the volatility of rates of returns to endowments - during the period 2005 to 2014 they ranged from negative 18.7 percent to

9 The calculations regarding operating revenue in this paragraph are based on Kirshstein and Hurlburt (2012, pp. 7-10), who provide information on the sources of operating revenue by type of institution for each year during the period 2000-2010. 
positive 19.2 percent (Sherlock et al. ,2015, p. 14) - the share of operating budgets funded by endowments has not exhibited any discernible trends.

Rates of return on endowments vary not only from year to year, but across institutions in a given year. On average, the larger is an endowment, the higher is its rate of return. In 2014, the 10 year return was 8.2 percent for schools whose endowments exceeded a billion dollars, but only 6.6 percent for schools with endowments under \$25 million (Sherlock et al., 2015, p. 13). Lerner, Schoar and Wang (2008) note that little work has been done on the determinants of endowments’ rates of returns, but do document some interesting tendencies in the data. In particular, more selective institutions tend to have higher returns. They conjecture that selective institutions "benefit from superior investment committees...more highly-skilled investment managers, and the broader knowledge bases and social networks of the schools themselves” (p. 208). They also note that over time schools have shifted their portfolios to so-called alternative assets (such as hedge funds, private equity funds, venture capital funds, oil and gas, and commodities). However, there is some evidence that "superior endowment performance may be due not just to asset class allocation, but also to selection of assets within each class” (p. 216).

Given the volatility in rates of return, it is not surprising that no general statements can be made regarding the relative importance of market returns and contributions to the growth of endowments. For example, according to Sherlock et al.'s (2015, p.22) tabulations from Internal Revenue Service data, in 2011 net investment earnings were $\$ 1.5$ billion less than contributions, while in 2012 they were $\$ 25$ billion greater. 
Theoretical models of payout behavior. Every theoretical model of endowment payouts makes assumptions about university objectives and then derives results pertaining to the role of endowments in supporting these objectives. Analyzing endowment payout behavior is a particularly challenging problem because consensus about these objectives is lacking. An important class of models assumes that, in general terms, the university's goal is to ensure intergenerational equity. ${ }^{10}$ As shown by Tobin (1974), a university with this objective should use its endowment to provide a smooth flow of real income to support its activities. Much the same conclusion is reached by Litvack, Malkiel and Quandt (1974). In a subsequent contribution, Dybvig (1999) posits a similar objective but assumes that, in addition, university decision makers seek to avoid paying out less than they did in the prior year. Dybvig shows that given this objective, payout values increase in the years following positive shocks, but less so than the increase in the portfolio value, so the payout rate decreases. Because the amount paid out never falls even after a negative shock, this implies that the payout rate increases after a negative shock because the value of the endowment is lower. Gilbert and Hrdlicka (2013) also assume that the university's objective is to promote intergenerational equity, but they explicitly take into account the higher risk to future generations of asset allocations that produce high returns. They show that under this assumption payout values should increase and decrease symmetrically in response to positive and negative return shocks.

A related but alternative assumption regarding the university's objective is that it seeks to hedge against unexpected changes in "background income," defined as nonendowment sources of revenue such as tuition, grants from the government, and gifts

10 According to a 2004 Commonfund survey of university administrators, this objective of endowments is generally considered among the most important. 
(Merton, 1993). In colloquial terms, the endowment serves as a "rainy day fund.” ContiBrown (2011, p. 709) argues that with this objective, universities accumulate wealth in order to mitigate the effects of substantial negative shocks to background income. Under this hypothesis, payout rates would increase in years with negative background income shocks, but would not necessarily be related to endowment shocks.

This entire approach to conceptualizing endowment strategy has been challenged. Hansmann (1990) argues that the actual investment and payout policies of endowments are inconsistent with the objective of pursuing intergeneration equity or providing for a rainy day. He notes, "The maintenance of an endowment is often viewed as an objective in its own right, rather than as simply a means to an end.” Pursuing this notion, ContiBrown (2015, p. 737) argues that the university's goal is to assure that the endowment never loses its value. He notes that this is an old idea, quoting from a 1922 treatise which asserted that an endowment "is sacred and should not be touched or encroached upon for any object whatsoever" (p. 737). As a "symbol of status and prestige" (Conti-Brown 2011), maximization of the value of the endowment is an end in itself. ${ }^{11}$ As noted by Brown et al. (2014), an implication is that payout values and payout rates will tend to remain unchanged after positive endowment shocks but decline after negative endowment shocks.

Another reason that endowment managers might not pursue the goal of intergenerational equity is agency problems. Hansmann (1990) argues that agency issues could potentially lead to either under-spending and over-spending (relative to the

11 Although the U.S. News and World Report ranking formula does not include endowment size per se, financial resources per student is an important factor, meaning that schools with large endowments tend to receive higher ranks, ceteris paribus (Morse 2012). 
benchmark of expenditure smoothing). Under-spending could allow the university to accumulate resources and make the jobs of endowment managers more secure, while over-spending could be a strategy for administrators who care more about pleasing current students and faculty than about preserving resources for future generations.

Empirical tests. While there is a substantial theoretical literature on the normative aspects of endowments payouts, empirical work is rare. ${ }^{12}$ Brown et al. (2014) examine the effect of endowment shocks on payouts. As noted above, a major challenge is to operationalize the concept of a shock. They assume that the shock in a given year is proportional to the return on the endowment in that year. More precisely, they compute a university's shock in a given year by multiplying the return on the endowment portfolio by the ratio of the previous year's endowment value to total university costs. The argument is that changes in the endowment return will be of greater impact to universities that rely more heavily on their endowment to cover their costs. While this might be the case, it is not clear whether this tells us anything about shocks. To see why, denote the portfolio return of university $i$ in year $t$ as $S_{i t}$. Imagine that one is examining the time series behavior of a single institution. Suppose further that a university's endowment is fully invested in an asset (say a certificate of deposit) that provides a certain positive return of three percent annually. According to Brown et al.'s definition, this hypothetical institution would experience a positive endowment shock every single year, even though the realized return is entirely foreseen. Thus, this formulation does not embody any notion of a shock as a surprising event, or in more technical terms, the difference between the expected value of a variable and its realization.

12 Conti-Brown (2011, pp. 744-747) provides thumbnail case studies of how five elite institutions adjusted their spending in the aftermath of the financial crisis of 2008. He concludes that these institutions did not use their endowments to avoid budgetary disruptions. 
Brown et al.'s actual model is more complicated, because it is estimated using panel data and includes university fixed effects. Thus, the variable that enters the regression in year $t$ is essentially $S_{i t}-\bar{S}_{l}$, where $\bar{S}_{\imath}$ is the mean of $S_{i t}$ over the time series observations for university $i$. If one is willing to interpret $\bar{S}_{\imath}$ as the university's expected (normalized) return in every year of the sample period, then this variable is, by definition, the difference between the expected and actual value - a shock. However, because $\bar{S}_{\iota}$ is the mean over all the time series observations, this interpretation implicitly rests on the assumption that universities' expectations in year $t$ are generated in part on the basis of information that is unknown at the time the expectation is formed (except when $t$ is the very last year of the sample).

A closely related issue concerns the use of Brown et al.'s shock measure for classifying observations as having positive or negative shocks. Their shock variable is far more likely to be positive than it is to be negative, because in most years, endowments earn a positive rate of return. Indeed, using their approach, 75 percent of the observations in their sample exhibit positive shocks. The median shock is only negative in four out of 23 years of data, falling below zero only in years of particularly poor performance: the dot-com bubble burst of 2001-2002 and the Great Recession of 2008-2009. This means that the observations characterized as "negative shocks” are exclusively extreme negative shocks, while the observations characterized as "positive shocks” are a mixed bag, including observations that are a bit below the sample period mean, a bit above the mean, and well above the mean. The negative payout response to negative shocks is driven by a few very extreme observations, while the few extreme positive observations are in the same bin with a number of positive but small rates of return, which tends to render the 
impact of positive shocks insignificant. In short, this algorithm for classifying shocks builds in a bias to finding asymmetric responses to the two types of shocks.

\section{Data}

Our primary data come from the National Association of College and University Business Officers (NACUBO). These data are proprietary and confidential. However, NACUBO grants access to researchers with bona fide research proposals. ${ }^{13}$ NACUBO began its survey of university endowments in 1984, and collects yearly data on assets under management (endowment value), investment returns net of fees and expenses, and actual payout rates from the endowment, inter alia. NACUBO encourages universities to participate in the survey by rewarding those who do with access to the dataset, thus allowing them to learn about trends in the investment strategies of other universities. The number of institutions submitting data to NACUBO has increased steadily from 200 in 1984 to 778 in 2009. This means that the dataset does not provide complete information for all universities every year. On average, endowment size and rate of return figures are only reported for 16 of the 28 years in the dataset. Furthermore, NACUBO added the question about payout rates from the endowment to their survey in 1993, so this variable is unavailable in earlier years.

We also incorporate data from the Integrated Postsecondary Education Data System (IPEDS), which includes institutional information such as revenue and expenditure streams and fixed characteristics of the university, such as its degree-granting status and whether it is public or private. Schools submit information to this survey on an

13 Other studies using these data include Brown, Garlappi and Tiu (2010), Dimmock (2012), and Brown et al. (2014). 
annual basis. For most variables, this dataset extends from 1987 to 2009. Combining the two datasets yields annual observations for 778 institutions between 1993 and 2009. These institutions comprise approximately one-third of all four-year universities. Given that the NACUBO survey is voluntary, those universities that have endowments and therefore care most about trends in endowment policies at other schools are more likely to participate. Therefore, these schools are not a random sample of all four-year institutions, but still represent an important segment of U.S. higher education.

Summary statistics for the analysis sample (i.e., schools for which both IPEDS and NACUBO data are available) are provided in Table 1. The top panel presents the distribution of universities in the sample by institution type (public or private) and the four largest categories of degree type in the sample. The second panel shows a number of other university characteristics, including size, selectivity, proportion of students with federal Pell grant eligibility, and student demographic characteristics.

The third panel exhibits summary statistics for key variables from the NACUBO dataset, including end-of-year endowment value, yearly endowment real growth rates, and payout rates. Note that the average endowment size, $\$ 435$ million, is over four times the median of $\$ 95$ million. This reflects the well-known fact that a relatively small number of “super-endowments," such as Harvard’s endowment of over $\$ 35$ billion, skew the mean upwards. In our sample, the growth rates of endowments varied considerably both across universities and over time. The 1990s and the period from 2003-2007 saw high yearly growth rates. On the other hand, endowment values declined on average during the recessionary periods 2001-2002 and 2008-2009. The impact of the Great Recession was particularly pronounced, with endowment values falling by an average of 
over 20 percent. However, these trends must be interpreted cautiously because, as noted above, the composition of the NACUBO sample has been changing over time as more universities enter the survey.

The range of payout rates is much narrower than the ranges of endowment sizes and their growth rates. Consistent with the stated payout policies of many universities, the modal payout rate is 5 percent, although the mean and median are below 5 percent.

As noted above, one expects that there will be differences between our analysis sample (which includes only schools that respond to the NACUBO survey), and the entire universe of four-year institutions. Table 2 documents these differences. For convenience, the left hand side reproduces information from Table 1 on the analysis sample, and the right hand side shows comparable information for all schools included in the IPEDS data. The table indicates that schools in the analysis sample are more likely to be private institutions, more likely to offer advanced degrees, have larger student populations (with smaller proportions of black and Hispanic students), and are more selective.

\section{Methodology}

\subsection{Basic Setup}

In this section, we develop an empirical framework for testing how contemporaneous and lagged shocks to the value of the endowment affect payouts. The first step in such a process is to formalize the notion of shocks. We define a shock to be the difference between what is expected and what is actually observed. Because the expectations of universities regarding the value of their endowment in a given year are 
not observable to the econometrician, these expectations (and the corresponding residuals) must be constructed. The second step is to use the constructed shocks as regressors in an equation where the relevant response is the dependent variable.

Estimating shocks. Our method for constructing endowment shocks reflects an approach that is common in a variety of contexts. To begin, note that at the beginning of year $t$, all that decision makers have to go on when making predictions is information that is known in year $t-1$. Now assume that decision makers believe that the actual value of the variable in year $t$ depends in a systematic fashion on certain variables known in year $t-1$ as well as a random error. One can then estimate a regression of the value of the endowment in year $t$ on these lagged variables. In effect, the regression represents the process that decision makers use to forecast the future value of the endowment. With the estimates of such a regression in hand, one can predict the value of the endowment in year $t$ given the information known in year $t-1$, simply by substituting the information from year $t-1$ into the regression. This predicted value will generally differ from the actual value due to the random component. The shock in year $t$ is the difference between the actual value and the forecast made on the basis of the regression. ${ }^{14}$

To implement this procedure, one must specify the relevant variables from $t-1$. We adapt the simple and appealing approach used by Blinder and Deaton (1985) in their study of consumption behavior. The structure of their problem is similar to ours - they analyze how shocks to household income affect consumption; we are examining how shocks to endowment value affect the amount of university consumption financed by the endowment. Basically, Blinder and Deaton assume that current income in year $t$ can be

14 This general approach has been used in a variety of contexts. See, for example, Vissing-Jorgensen (2002), Jurado et al. (2015) and Attanasio et al. (2015). 
predicted knowing income in year $t-1$ and income in year $t-2$. That is, they estimate a regression of income in year $t$ on two of its lags. The predicted value of income in a given year is the forecast generated by this regression. The shock is the residual, the difference between the expected and realized values.

Adopting this approach to the problem of forecasting endowment value, we estimate the following model:

$$
\ln V_{i t}=\beta_{0}+\sum_{a=1}^{2} \beta_{a} \ln V_{i, t-a}+\theta_{1} \text { public }_{i}+\theta_{2} \text { doctoral }_{i}+\theta_{3} \text { master }_{i}+\varepsilon_{i t}
$$

where $V_{i t}$ is the inflation-adjusted value of school $i$ 's endowment in year $t .^{15}$ The other regressors are dichotomous variables for the type of university and the highest degree it grants. public $_{i}$ equals one if university $i$ is a public institution, doctoral ${ }_{i}$ equals one if university $i$ offers doctoral degrees, and master $s_{i}$ equals one if the highest degree offered by university $i$ is a master's degree. These variables are included to allow for the possibility that, in the absence of shocks, the endowments of different types of universities grow at different rates. ${ }^{16}$

Other variables known before period $t$ could possibly belong in the forecasting equation. To the extent that any such omitted variables are correlated with payouts from the endowment, then our estimates of the impact of shocks on payouts will be biased. Put another way, the model's validity rests on the assumption that any

15 The inflation adjustment is done using the HEPI (Higher Education Price Index). (See Griswold (2006)). However, our substantive results do not change when we adjust by the CPI instead. Some schools have zero endowments, so for these observations, the logarithm of $\mathrm{V}$ is not defined. To deal with this issue, we calculate $\ln (\mathrm{V}+1)$ rather than $\ln (\mathrm{V})$. Given that $\mathrm{V}$ is large, $\ln (\mathrm{V})$ is very close to $\ln (\mathrm{V}+1)$. When $\mathrm{V}$ is $0, \ln (0+1)=0$, so there are no undefined values. We use the same convention throughout this paper when taking logarithms of variables.

16 Lerner et al. (2008) show that endowments at Ivy League universities and schools with high average SAT scores tend to generate higher returns than other schools. 
variables omitted from the first stage are not correlated with the dependent variable in the second stage, an assumption that is common in all econometric procedures of this kind. The approach taken here is attractive because it is simple, tractable, and has been found to be fruitful in other contexts. ${ }^{17}$

An econometric complication arises due to the presence of a mechanical relationship between endowment growth and payouts from the endowment—-the greater that payouts are in a given year, the lower is the growth of the endowment, other things being the same. To deal with this issue, we estimate equation (1) using instrumental variables for $V_{t-1}$ and $V_{t-2 .}$. A suitable instrumental variable must satisfy two criteria. First, it needs to be correlated with the endogenous variable, and second, it must not belong in the equation itself. Variables that satisfy these criteria are $V_{0 t-1}$ and $V_{0 t-2,}$ defined as the values of the endowment that would have obtained if payouts had been zero in years $t-1$ and $t-2$, respectively. This is similar to the approach often used in the empirical literature on the impact of the tax deductibility of charitable donations, in which there is a mechanical relationship between donations and marginal tax rates (because when charitable deductions increase, the marginal tax rate decreases). Instead of using the actual marginal tax rate, researchers include in their models a synthetic marginal tax rate calculated on the basis of some hypothetical exogenous amount of charitable contributions, generally zero. (See, for example, Feenberg (1987) and Auten, Sieg and Clotfelter (2002)).

We calculate the one-period-ahead prediction as the expectation of endowment value (denoted exp_endow $_{i t}$ ), and the estimated $\varepsilon_{i t}$ 's are the endowment shocks

17 See, for example, Vissing-Jorgensen's (2002) study of the impact of shocks to background income on household portfolio decisions. 
(denoted endow_shock $k_{i t}$ ). Following Brown et al. (2014), we test for possible

asymmetries in the response to positive and negative endowment shocks by treating them as two separate variables:

$$
\begin{aligned}
& \text { pos_endow_shock }_{i t}=\max \left[0, \text { endow_shock }_{i t}\right] \\
& \text { neg_endow_shock }_{i t}=\min \left[0, \text { endow_shock }_{i t}\right] .
\end{aligned}
$$

The effect of shocks on payouts. With the expected and unexpected components of endowment value for each university and year in hand, we turn to the second stage equation. ${ }^{18}$ In all specifications, the left-hand side is the outcome variable of interest, $Y_{i t}$. On the right-hand side of the second stage equation we include the contemporaneous and lagged values of both the expected and unexpected values of the logarithm of endowment value, time effects $\left(\gamma_{t}\right)$, and university fixed effects $\left(\delta_{i}\right)$. Time effects control for factors that affect all institutions' decisions in a given year, such as the macroeconomic environment and the state of the financial markets. University fixed effects account for all unchanging university characteristics, including the governance structure of the endowment. ${ }^{19}$ Our specification also allows for asymmetric responses to positive and negative shocks: $:^{20}$

18 In order to reduce the influence of outliers, we delete observations in the top one percent of the distribution of endowment growth rates for the second stage regression. Endowments for several institutions grew at very high rates in some years due to, for example, extraordinary gifts. (The maximal annual growth rate in the NACUBO data is 12,000 percent. At the one percent cutoff, the growth rate is a 70 percent.)

19 To the extent that there are exogenous time-varying characteristics that are also correlated with the shocks, the coefficients on the shock variables will be inconsistent. Given the relatively short time period of our data, we doubt that this is likely to be a problem.

20 This specification does not include shocks to any revenue sources other than the endowment. Following Brown et al., we experimented with augmenting equation (4) with the expected and unexpected values of government grants, but found that these variables did not add significantly to the explanatory power of the model. 


$$
\begin{aligned}
Y_{i t}=\alpha_{0}+\alpha_{1} \text { pos_endow_shock } k_{i t}+\alpha_{2} \text { neg_endow_shock } k_{i t} \\
+\alpha_{3} \text { pos_endow_shock } k_{i, t-1}+\alpha_{4} \text { neg_endow_shock } k_{i, t-1} \\
+\alpha_{5} \text { exp_endow }_{i t}+\alpha_{6} \exp _{-} \text {endow } w_{i, t-1}+\gamma_{t}+\delta_{i}+\omega_{i t} .
\end{aligned}
$$

Two considerations need to be taken into account when estimating the standard errors in equation (4). First, one should cluster standard errors at the university level to allow for correlations among errors for a given university over time. Secondly, since several of the regressors are generated by a first stage regression, OLS standard errors will not be correct. Two-stage least squares is not appropriate given that the first stage itself has to be estimated by instrumental variables due to the mechanical relationship between endowment values and endowment payouts. We therefore use the method of clustered bootstrapping to generate standard errors throughout the analysis (Efron and Tibshirani 1986).

\subsection{Interpreting the coefficients}

It is useful to think about what the signs of the various coefficients in equation (4) would be if institutions followed a conventional payout rule - spending in the current year is some given percentage of a moving average of past values of the endowment. ${ }^{21}$ Imagine that an institution experiences an unexpected increase in the value of its endowment in year $t$. Given that the payout rule stipulates that spending depends on a moving average of past endowment values, then this would have no effect on the amount paid out in year $t$, so that $\alpha_{1}$ would be zero. In year $t+1$, the shock in year $t$ would increase the moving average, so the amount paid out would increase, that is, $\alpha_{3}$ would be positive. A symmetrical argument applies to negative shocks; with an unexpected

21 As noted above, for most universities, the average is taken over the past three years. 
decrease in the value of the endowment, we would expect $\alpha_{2}$ to be zero and $\alpha_{4}$ to be positive. Similarly, an increase in the expected value of the endowment in year $t$ would have no effect on the amount paid out in that year $\left(\alpha_{5}=0\right)$ but a positive effect in year $t+1\left(\alpha_{6}>0\right)$

If, in contrast, universities systematically deviate from their payout policies, we would not expect these predictions to hold. For example, if universities are endowment hoarders, they respond asymmetrically to positive and negative shocks. In its strongest form, the endowment hoarding hypothesis suggests that universities reduce payouts in response to negative shocks but do not change payouts in response to positive shocks. In this case, either coefficient $\alpha_{2}$ or $\alpha_{4}$ would be positive while coefficients $\alpha_{1}$ and $\alpha_{3}$ would both be zero. In a less extreme version of the hypothesis, $\alpha_{1}$ and $\alpha_{3}$ could be positive, but less than the coefficients on the negative shocks.

\section{Results}

\subsection{First stage results}

The top panel of Table 3 shows the estimated coefficients of equation (1), and the bottom panel shows the associated summary statistics for the shock variables. Note that the dollar figures in the bottom panel are entered as logarithms.

\subsection{Effects of shocks on payout values}

Before presenting the regression results, we examine a simple graphical depiction of the relationship between endowment shocks and amounts paid out from the endowment. Figure 1a shows the average endowment shock in each year together with the logarithm of the amount paid out (note that the graphs for the two variables are scaled 
differently to allow comparisons of their trends). The endowment shocks are distributed fairly evenly around zero, which is the average value by construction. They are consistent with what one would guess given recent financial market history. In particular, the largest negative shocks are in 2001-2002 and 2008-2009. The endowment shocks and amounts paid out tend to move together - when the average value of one variable increases, the average value of the other tends to increase as well.

Figure $1 \mathrm{~b}$ is similar, but plots one-period lagged rather than contemporaneous endowment shocks. The two series graphed in Figure 1b move together even more closely. Taken together, Figures 1a and 1b suggest that there is a positive relationship between endowment shocks and payout values, and that this relationship is stronger for lagged endowment shocks than for contemporaneous shocks. Of course, more definitive results require a multivariable approach, to which we now turn.

We first estimate equation (4), in which positive and negative endowment shocks are constrained to have the same effects. The results are presented in Table 4. One cannot reject the hypothesis that the coefficient on endow_shock $k_{i t}$ is zero. Hence, a shock to the value of the endowment in a given year has no statistically significant effect on the amount of money paid out of the endowment that year. However, the coefficient on the lagged value of the shock is significant at the one percent level and implies that an unexpected 10 percent increase (decrease) in the value of the endowment results in a 13.9 percent increase (decrease) in the amount paid out from the endowment in the following year. Note that the sum of the contemporaneous and lagged coefficients is positive and one can reject the hypothesis that this sum is zero. This shows that the net effect of endowment shocks over a two-year period is significant and in the direction of the shock. 
Proceeding down the table, a similar story holds for the effect of the expected endowment value on amounts paid out. An increase (decrease) of 10 percent in the expectation of the endowment value in year $t-1$ increases (decreases) payouts by 14.1 percent in year $t$, while changes in the current year's expected endowment have no significant effect. As shown above, these results are all consistent with the notion that universities are not hoarding their endowments.

However, this specification does not allow us to examine whether payments from endowments respond asymmetrically to positive and negative shocks. To address this issue, we next enter positive and negative shocks separately, as described by equations (2) and (3). When interpreting these results, which are presented in Table 5, it is important to recall from equation (3) that neg_endow_shock ${ }_{i t}$ is the algebraic value of the shock, so that it is always a negative number. Thus, a bigger negative shock is a smaller numerical value, and correspondingly, a positive coefficient on neg_endow_shock $k_{i t}$ means that the greater the negative shock, the greater the decrease in payouts, ceteris paribus. Column (1) displays the results of a model with only contemporaneous values of expected and unexpected changes in endowment values (along with year and university fixed effects) on the right hand side. We find that neither positive nor negative contemporaneous shocks have a statistically significant effect on payouts. Further, the coefficient on positive shocks is not significantly different from the coefficient on negative shocks. Finally, the effect of the current expected value of the endowment is significant, but, as shown below, this significance disappears when the lagged expectation is included. Taken together, these results suggest that universities tend not to alter payouts during a given year based on contemporaneous information about shocks to 
their endowment - a finding consistent with stated payout policies but not endowment hoarding.

In column (2), we include the lagged values of the positive shock, negative shock, and expected endowment value. These three variables are each significant at the one percent level, while the respective contemporaneous values are all insignificant. The point estimates suggest that an unexpected 10 percent increase in lagged endowment value increases the amount paid out by approximately the same percentage that an unexpected decrease in lagged endowment value reduces it - about 13 percent. One cannot reject the hypothesis that the response to positive and negative shocks is symmetrical, both for contemporaneous and lagged shocks. This again contradicts the predictions of the endowment hoarding hypothesis. Looking at the net effect of endowment shocks on payout values over the current and next year (by adding together the respective current and lagged values), a positive shock significantly increases the amount paid out while a negative shock significantly decreases it.

\subsection{Alternative Specifications}

In order to assess the robustness of our results, we re-estimated our model several different ways.

Time trends. Our baseline model has annual time effects. We re-estimated the model using linear and quadratic time trends instead. The estimates with these smooth time trends, which are reported in Appendix Table A.1, indicate that during our sample period, payouts increased by about 4.7 percent annually, other things being the same. Importantly, the coefficients on the contemporaneous and lagged endowment shocks are 
quite similar to their counterparts in Table 5, suggesting that our substantive results are essentially unchanged.

Additional lags. The advantage of having one lag of the shocks in our baseline equation is that it is simple, and maximizes the number of observations available to estimate the model. Nevertheless, given that many universities’ stated payout rules depend on the last three years' worth of endowment values, it makes sense to check whether our results are sensitive to the inclusion of additional lags. We therefore reestimated equation (4) with both the second and third lags of the endowment shocks. The results, which are reported in Appendix Table A.2, indicate that: 1) The first lags remain positive and significant; 2) The second and third lags are statistically insignificant; and 3) One cannot reject the hypothesis that the first lags of the positive endowment shock and the negative endowment shock are the same $(\mathrm{p}=0.21)$. In short, our substantive results are robust to the inclusion of additional lagged values of the shocks.

\section{Alternative measure of shocks. As mentioned in Section 2 above, Brown et al.} (2014) use the product of the annual rate of return on the endowment and the ratio of the start-of-year endowment value to total university costs as their measure of shocks. They find that the contemporaneous positive and negative shocks measured in this fashion have statistically different effects on payout rates, which they interpret as evidence in favor of the endowment hoarding hypothesis. We argued above that their method for characterizing shocks has serious drawbacks. Nevertheless, it is of some interest to estimate their model using our data set, which covers both a longer time period and has a more extensive set of institutions than theirs. ${ }^{22}$ Specifically, we estimate the model from

22 Our data set has more time series observations, starting in 1987 rather than 1993 . Further, our sample includes all institutions. In contrast, Brown et al. include only universities that grant doctoral degrees, 
their Table 4 (column 2), in which the left hand side variable is the payout rate in period $t$, and the right hand side variables include contemporaneous and lagged positive and negative shocks (calculated using their approach), university fixed effects, and year effects.

The results are reported in Appendix Table A.3. For our purposes, the key finding is that, contrary to Brown et al., one cannot reject the hypothesis that the contemporaneous positive and negative shocks are the same $(\mathrm{p}=0.24)$. Thus, even using their measure of shocks, we do not find evidence in support of endowment hoarding. The discrepancy between our calculations and theirs suggests that the econometric evidence in favor of the endowment hoarding hypothesis is, at a minimum, somewhat fragile.

\section{Conclusions}

Universities’ practices with respect to the management of their endowments are under scrutiny by politicians and commentators. Criticisms of universities have been fueled by the assertion that increases in tuition have made college attendance unaffordable for many families at the same time that endowments have been growing at an enormous rate. It appears to such critics that institutions are accumulating endowment wealth for its own sake, rather than to advance the public good. They find this situation particularly objectionable because a number of public policies favor endowment accumulation. Two of the most important are the exemption of endowment returns from

arguing that longer time series data are available for such schools and that endowments tend to be larger and thus more important for doctoral schools. However, in our data, on average doctoral institutions have only 2 more years of time series data than non-doctoral institutions. Furthermore, in our data, 196 doctoral schools and 168 non-doctoral schools had endowments valued at more than \$100 million in 2009. Therefore, by limiting the sample only to doctoral institutions, one would throw out roughly half of the schools with large endowments. 
taxation and the absence of any requirement that endowments pay out some proportion of their value each year to support their activities (including student aid). Although no formal legislative proposals are currently under consideration, it appears likely that a bill to enact some kind of mandatory payout regime will be introduced in Congress in coming years.

The leaders of universities with substantial endowments have countered that financial aid has, in fact, increased substantially as endowments have grown. More relevant for this paper, they also claim that endowments play a critical role in supporting the long-run viability of their institutions. Inter alia, endowments allow universities to smooth expenditures over time and assure that future generations of faculty and students will have resources that are adequate to support the production and dissemination of knowledge.

Which view of university endowments is more in accord with reality? Theoretical models show how one can make inferences regarding the goals of endowment managers by observing their payout policies. If, for example, the goal is to maximize the endowment, then payouts will be affected asymmetrically by external shocks to its value - payouts will fall more when the value of the endowment unexpectedly decreases than they rise when the value of the endowment unexpectedly increases. If the goal is intergenerational equity, then one would not expect to observe such a pattern.

Using a conventional approach to estimating shocks, we find that an unexpected change in the value of a university's endowment in a given year does not affect the amount paid out from the endowment in that year, but has a substantial effect on the amount in the following year. Furthermore, positive and negative shocks have 
symmetrical effects on payouts in the following year. In short, the data are not consistent with the notion of endowment hoarding. While we make no attempt to argue that the payout policies of endowments are optimal for the university or for society, our findings do indicate that fears that universities are abusing their tax-exempt status by hoarding their endowments may be misplaced.

Future research on endowment payout policies might proceed in a number of directions. For one, while our statistical procedure for decomposing changes in endowment values into expected and unexpected components is certainly not idiosyncratic, there are other approaches, ${ }^{23}$ and investigating the consequences of using alternative methods could be useful. Further, there is some evidence that the Great Recession changed the way financial decisions are made in various sectors of the economy. ${ }^{24}$ As more years of data become available, it would be interesting to see whether the behavior of university endowment managers has changed as well. That said, we believe that our results shift the burden of proof to those who argue that universities are endowment hoarders.

23 See, for example, White (1983).

24 See, for example, Shane (2013) on how banking practices have changed. 


\section{$\underline{\text { References }}$}

Attanasio, O., Meghir, C., and Mommaerts, C. (2015). Insurance in Extended Family Networks. National Bureau of Economic Research, Working Paper No. 21059.

Auten, G., H. Sieg and C.T. Clotfelter (2002). Charitable Giving, Income, and Taxes: An Analysis of Panel Data. American Economic Review 92(1), 371-382.

Blinder, A.S. and Deaton, A. (1985). The Time Series Consumption Function Revisited. Brookings Papers on Economic Activity, (2), 465-511.

Brown, J., Dimmock, S., Kang, J., and Weisbenner, S. (2014). How University Endowments Respond to Financial Market Shocks: Evidence and Implications. American Economic Review, 104(3), 931-962.

Brown, K.C., Garlappi, L., and Tiu, C. (2010). Asset Allocation and Portfolio Performance: Evidence from University Endowment Funds. Journal of Financial Markets, 13(2), 268-294.

Brown, K.C. and Tiu, C. (2013). The Interaction of Spending Policies, Asset Allocation Strategies, and Investment Performance at University Endowment Funds (No. w19517). National Bureau of Economic Research.

Cejnek, G., Franz, R., Randl, O., and Stoughton, N. (2013). A Survey of University Endowment Management Research. Available at SSRN 2205207.

Cejnek, G., Franz, R., and Stoughton, N. (2014). An Integrated Model of University Endowments. Available at SSRN 2348048.

Conti-Brown, P. (2011). Scarcity Amidst Wealth: The Law, Finance, and Culture of Elite University Endowments in Financial Crisis. Stanford Law Review, 63(3), 699-749.

Coy, P. (2009). “Academic Endowments: The Curse of Hoarded Treasure.” Bloomberg Business, March 01. www.bloomberg.com.

Dimmock, S.G. (2012). Background Risk and University Endowment Funds. Review of Economics and Statistics, 94(3), 789-99.

Efron, B. and Tibshirani, R. (1986). Bootstrap Methods for Standard Errors, Confidence Intervals, and Other Measures of Statistical Accuracy. Statistical Science, 1(1), 54-75.

Feenberg, D. (1987). Are Tax Price Models Really Identified: The Case of Charitable Giving. National Tax Journal, 40(4) , 629-633.

Gilbert, T. and Hrdlicka, C.M. (2014). Why are University Endowments Large and Risky? Available at SSRN 1787372. 
Griswold, J. (2006). “What’s the Best Yardstick to Measure Inflation?” Commonfund Institute. http://www.commonfund.org/CommonfundInstitute/HEPI/Pages/Best YardsticktoMeasureInflation.aspx (accessed February 13, 2014).

Grassley, C. (2011). “College Tuition Hikes Come Despite Tax-favored Asset Hoarding.” Press Release. http://www.grassley.senate.gov/news/Article.cfm?customel_dataPage ID_1502=38191 (accessed March 21, 2014).

Hansmann, H. (1990). Why Do Universities Have Endowments? Journal of Legal Studies, 19(1), 3-42.

Jurado, K., S.C. Ludvigson, and S. Ng (2015). “Measuring Uncertainty.” American Economic Review 105(3), 1177-1216.

Joint Committee on Taxation, General Explanation of the Economic Recovery Tax Act of 1981, US Government Printing Office, Washington, 1981.

Kirshstein, Rita J. and Steven Hurlburt, Revenues: Where Does the Money Come From? A Delta Data Update, 2000-2010, American Institutes for Research, 2012, http://www.deltacostproject.org/sites/default/files/products/Revenue_Trends_Production. pdf.

Lerner, J., Schoar, A., and Wang, J. (2008). Secrets of the Academy: The Drivers of University Endowment Success. Journal of Economic Perspectives 22(3), 207-22.

Litvack, J.M., Malkiel, B.G., and Quandt, R.E. (1974). A Plan for the Definition of Endowment Income. American Economic Review, 64(2), 433-37.

Merton, Robert C., “Optimal Investment Strategies for University Endowment Funds,” in Clotfelter, Charles T. and Michael Rothschild (eds.) Studies of Supply and Demand in Higher Education, 1993, pp. 211-236.

Morse, Robert. Rise in Endowments May Impact Best Colleges’ Rankings. USNews.com. US News \& World Report, 9 February 2012.

National Association of College and University Business Officers. 1986-2009. “NACUBO Annual Endowment Survey.” Proprietary data.

National Association of College and University Business Officers, Nacubo-Commonfund Study of Endowments, 2015, http://www.nacubo.org/Research/NACUBO-

Commonfund_Study_of_Endowments.html.

National Center for Education Statistics. 1987-2013. “Integrated Postsecondary Education Data System.” United States Department of Education. 
Seltzer, Rick, “Congressman Discusses Plan to Force Colleges to Spend Large Endowments,” Inside Higher Ed, May 12, 2016,

https://www.insidehighered.com/news/2016/05/12/congressman-discusses-plan-forcecolleges-spend-large-endowments.

Shane, S. (2013). How Small Business Credit has Changed Since the Great Recession. Small Business Trends. http://smallbiztrends.com/2013/06/how-small-business-credithas-changed-since-the-great-recession.html (accessed June 10, 2015).

Sherlock, Molly F., Jane G. Gravelle, Margot L. Crandall-Hollick and Jeffrey M. Stupak, College and University Endowments: Overview and Tax Policy Options, Congressional Research Service, December 2015.

Tobin, J. (1974). What Is Permanent Endowment Income? American Economic Review, 64(2), 427-32.

Vissing-Jorgensen, A. (2002). Towards an Explanation of Household Portfolio Choice Heterogeneity: Nonfinancial Income and Participation Cost Structures. National Bureau of Economic Research, Working Paper No. 8884.

White, F.C. (1983). Trade-off in Growth and Stability in State Taxes. National Tax Journal, 36(1), 103-14.

Wolf, Alexander M., "The Problems with Payouts: Assessing the Proposal for a Mandatory Distribution Requirements for University Endowments,” Harvard Journal on Legislation, volume 48, 2011. 591-622. 
Table $1^{\dagger}$

Summary Statistics

\begin{tabular}{|c|c|c|c|c|}
\hline University Type & Proportion & & & \\
\hline Public & $31.7 \%$ & & & \\
\hline Doctoral & $25.2 \%$ & & & \\
\hline Master’s & $30.6 \%$ & & & \\
\hline Bachelor - Liberal Arts & $17.3 \%$ & & & \\
\hline Bachelor - General & $11.8 \%$ & & & \\
\hline University Characteristics & Mean & $25^{\text {th }}$ percentile & Median & $75^{\text {th }}$ percentile \\
\hline \# of students (FTE equivalents) & 9,363 & 1,796 & 3,719 & 12,379 \\
\hline Acceptance rate & $65 \%$ & $54 \%$ & $69 \%$ & $79 \%$ \\
\hline$\%$ students Pell eligible & $26 \%$ & $16 \%$ & $23 \%$ & $32 \%$ \\
\hline School demographics: & & & & \\
\hline \% White & $69 \%$ & $61 \%$ & $77 \%$ & $86 \%$ \\
\hline \% Black & $7 \%$ & $2 \%$ & $4 \%$ & $7 \%$ \\
\hline \% Asian & $5 \%$ & $1 \%$ & $2 \%$ & $6 \%$ \\
\hline \% Hispanic & $4 \%$ & $1 \%$ & $2 \%$ & $5 \%$ \\
\hline Endowment Data & & & & \\
\hline & Mean & $25^{\text {th }}$ percentile & Median & $75^{\text {th }}$ percentile \\
\hline Endowment Size (\$ millions) & 434.6 & 38.16 & 95.07 & 287.4 \\
\hline Endowment Growth Rate (\%) & 7.2 & -3.7 & 6.4 & 13.7 \\
\hline Payout Rate (\%) & 4.8 & 4.1 & 4.9 & 5.4 \\
\hline
\end{tabular}

${ }^{\dagger}$ The first panel shows the distribution of universities in the sample by public or private status and the four largest categories of degree type according to the IPEDS data. The calculations in this panel are not weighted, i.e., they do not depend on the number of observations for each university in the analysis sample. The second panel shows a number of school characteristics from the IPEDS data, which are computed over all observations in the analysis sample. The third panel shows endowment information obtained from the NACUBO dataset, including the value of the endowment assets, the real growth rate of the value of the endowment, and the payout rate (defined as the percentage of the endowment made available for spending by the university in a given year). The statistics in this panel are also computed over all observations in the analysis sample. All dollar figures are in millions of 2010 dollars; the adjustment is made using the Higher Education Price Index. 
Table $2^{\dagger}$

Comparison of the Analysis Sample to the IPEDS Data

\begin{tabular}{|c|c|c|c|c|}
\hline \multirow[t]{3}{*}{ University Type } & \multirow{3}{*}{$\begin{array}{l}\text { Analysis } \\
\text { Sample } \\
\text { Proportion }\end{array}$} & \multirow{2}{*}{\multicolumn{3}{|c|}{ IPEDS }} \\
\hline & & & & \\
\hline & & \multicolumn{3}{|c|}{ Proportion } \\
\hline Public & $31.7 \%$ & \multicolumn{3}{|c|}{$50.4 \%$} \\
\hline Doctoral & $25.2 \%$ & \multicolumn{3}{|c|}{$5.5 \%$} \\
\hline Master’s & $30.6 \%$ & \multicolumn{3}{|c|}{$15.1 \%$} \\
\hline Bachelor - Liberal Arts & $17.3 \%$ & \multicolumn{3}{|c|}{$5.9 \%$} \\
\hline Bachelor - General & $11.8 \%$ & \multicolumn{3}{|c|}{$8.0 \%$} \\
\hline \multicolumn{5}{|l|}{ University Characteristics } \\
\hline & Analysis & Analysis & IPEDS & IPEDS \\
\hline & Sample & Sample & & \\
\hline & Mean & Standard Dev & Mean & Standard Dev \\
\hline \# of students (FTE equivalents) & 9,363 & 13,004 & 3,928 & 8,453 \\
\hline Acceptance rate & $65 \%$ & $19 \%$ & $83 \%$ & $33 \%$ \\
\hline \% students Pell eligible & $26 \%$ & $14 \%$ & $41 \%$ & $34 \%$ \\
\hline \multicolumn{5}{|l|}{ School demographics: } \\
\hline \% White & $69 \%$ & $24 \%$ & $64 \%$ & $32 \%$ \\
\hline$\%$ Black & $7 \%$ & $11 \%$ & $10 \%$ & $18 \%$ \\
\hline$\%$ Asian & $5 \%$ & $7 \%$ & $3 \%$ & $8 \%$ \\
\hline \% Hispanic & $4 \%$ & $7 \%$ & $6 \%$ & $15 \%$ \\
\hline \multicolumn{5}{|c|}{$\begin{array}{l}{ }^{\dagger} \text { The first panel shows the distribution of universities both in the analysis sample and in } \\
\text { the IPEDS data by private or public status and the four largest categories of degree type. } \\
\text { The calculations in this panel are not weighted, i.e., they do not depend on the number of } \\
\text { observations for each university in the samples. The second panel shows the summary } \\
\text { statistics for the two data sets for a number of school characteristics from the IPEDS data, } \\
\text { which are computed over all observations in the respective samples. }\end{array}$} \\
\hline
\end{tabular}


Table 3

Generating the Endowment Shocks

\section{3a. First Stage Regression ${ }^{\dagger}$}

\begin{tabular}{lc}
$\log (\text { endow_value })_{i t}$ & \\
\hline & \\
$\log (\text { endow_value })_{i, t-1}$ & $\left(0.908^{* * *}\right.$ \\
& $0.0755^{* * *}$ \\
$\log (\text { endow_value })_{i, t-2}$ & $(0.0181)$ \\
& 0.00547 \\
Public & $(0.0118)$ \\
& $0.0473^{* * *}$ \\
Doctoral & $(0.0137)$ \\
& -0.0177 \\
Masters & $(0.0118)$ \\
& $0.343^{* * *}$ \\
Constant & $(0.0719)$ \\
& \\
& 5,729 \\
Observations & 0.950 \\
R-squared & \\
\hline
\end{tabular}

3b. Expected and Unexpected Values of Endowments ${ }^{\dagger \dagger}$

Mean $25^{\text {th }}$ percentile Median $75^{\text {th }}$ percentile

Equation (1) - Endowment

Expected Value

18.58

17.71

18.61

19.66

Shock

0.13

$-0.07$

0.03

0.10

\footnotetext{
${ }^{\dagger}$ Panel 3a shows the estimates of the first stage equation, by which the log of endowment value at the end of the current year is predicted based on 2 lags of the log of endowment values and relevant university characteristics. The equation is estimated with instrumental variables and standard errors are in parentheses. Significance levels are indicated by:

$* 10 \%$, **5\%, ***1\% level.

"† Panel 3b shows summary statistics of the expectations and shocks for the log of endowment values as generated by the first-stage equation in Panel 3a. The figures are in logarithms of 2010 dollars.
} 
Figure $1^{\dagger}$

a) Average Contemporaneous Endowment Shocks and Payouts from Endowments

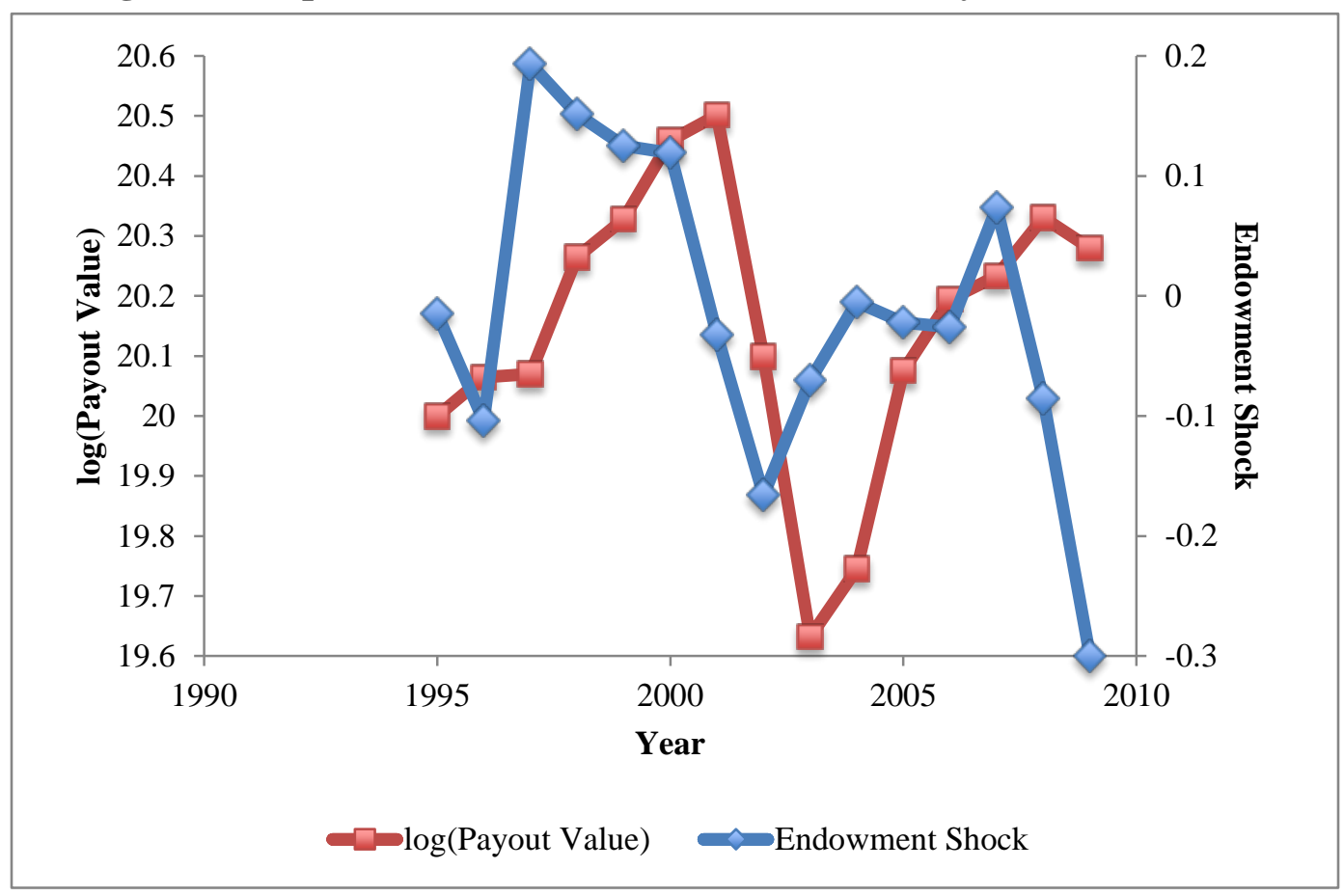

b) Average Lagged Endowment Shocks and Payouts from Endowments

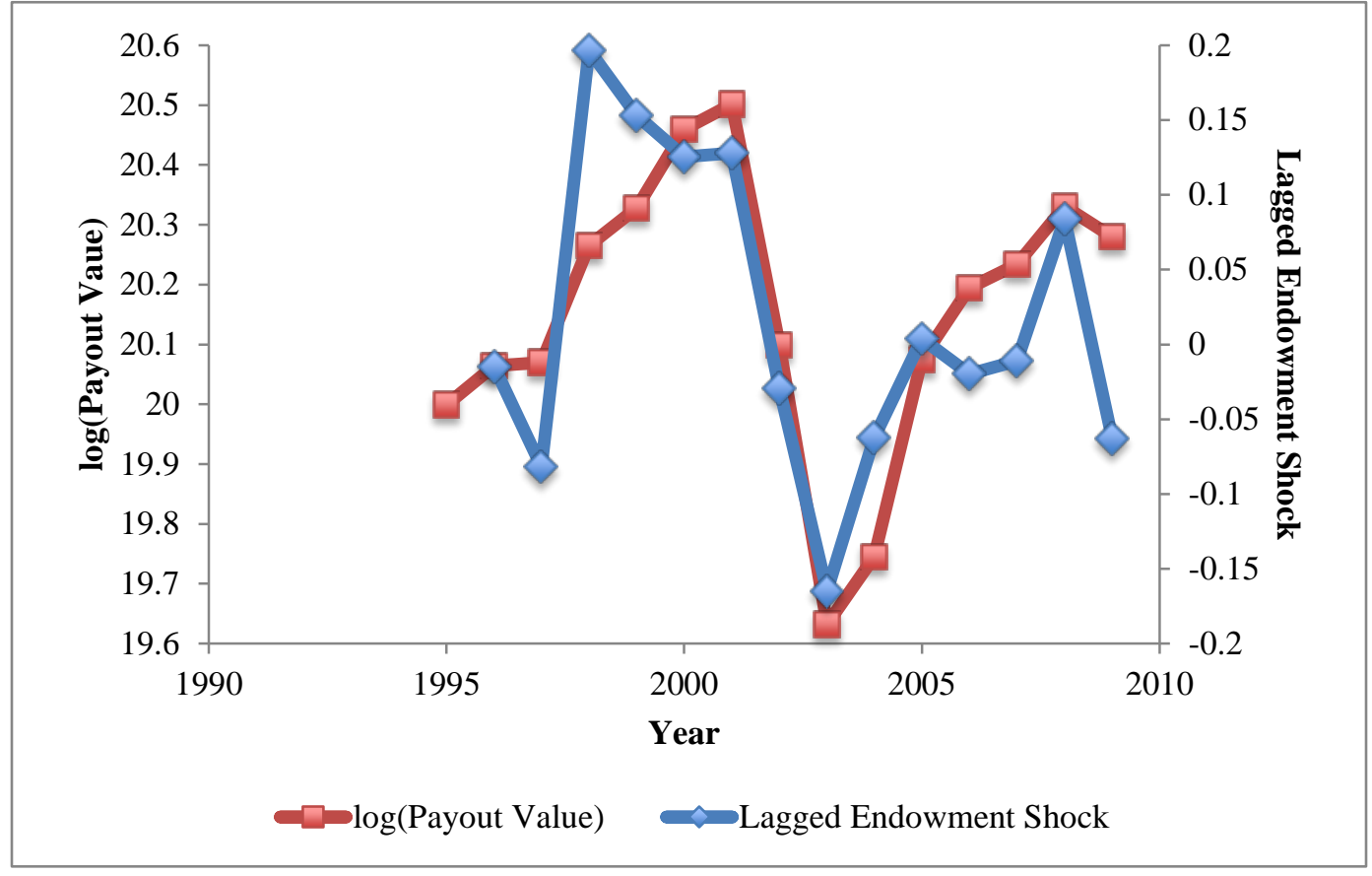

${ }^{\dagger}$ These figures show the trends over time in the logarithm of endowment payouts and endowment shocks. Payout data are from NACUBO. Endowment shocks are constructed using equation (1). 


\section{Table $4^{\dagger}$}

\section{Effect of Endowment Shocks on Payouts}

\begin{tabular}{lc}
\hline & $\log ($ Payout Value) \\
\hline endow_shock & \\
& -0.1543 \\
& $(0.1573)$ \\
endow_shock $_{i, t-1}$ & $1.386^{* *}$ \\
& $(0.613)$ \\
& -0.648 \\
exp_endow $_{i t}$ & $(0.652)$ \\
& $1.405^{* *}$ \\
exp_endow & $(0.675)$ \\
& \\
& 0.967 \\
Constant & $(2.050)$ \\
& \\
University fixed effects & Yes \\
Year fixed effects & Yes \\
& \\
Observations & 4,980 \\
R-squared & 0.203 \\
Number of Schools & 557 \\
\hline
\end{tabular}

${ }^{\dagger}$ This table shows the estimates of the model of the logarithm of endowment payouts with the effects of positive and negative shocks constrained to be the same. Expected and unexpected values of the endowment are constructed using equation (1). Clustered and bootstrapped standard errors are in parentheses. Significance levels are indicated by: $* 10 \%, * * 5 \%$, and $* * * 1 \%$ level. 


\section{Table $5^{\dagger}$}

Effect of Endowment Shocks on Payouts (Positive and Negative Shocks Entered Separately)

\begin{tabular}{|c|c|c|}
\hline & \multicolumn{2}{|c|}{$\log$ (Payout Value) } \\
\hline & $(1)$ & $(2)$ \\
\hline pos_endow_shock $k_{i t}$ & $\begin{array}{c}0.143 \\
(0.136)\end{array}$ & $\begin{array}{c}-0.206 \\
(0.127)\end{array}$ \\
\hline neg_endow_shock $k_{i t}$ & $\begin{array}{l}-0.565 \\
(0.364)\end{array}$ & $\begin{array}{l}-0.540 \\
(0.336)\end{array}$ \\
\hline pos_endow_shock $_{i, t-1}$ & & $\begin{array}{l}1.332 * * \\
(0.653)\end{array}$ \\
\hline neg_endow_shock $k_{i, t-1}$ & & $\begin{array}{c}1.331^{* *} \\
(0.621)\end{array}$ \\
\hline exp_endow $w_{i t}$ & $\begin{array}{c}0.841^{* * *} \\
(0.0920)\end{array}$ & $\begin{array}{l}-0.585 \\
(0.671)\end{array}$ \\
\hline exp_endow $w_{i, t-1}$ & & $\begin{array}{l}1.350 * \\
(0.706)\end{array}$ \\
\hline Constant & $\begin{array}{c}-0.726 \\
(1.710)\end{array}$ & $\begin{array}{c}0.811^{* *} \\
(1.861)\end{array}$ \\
\hline University fixed effects & Yes & Yes \\
\hline Year fixed effects & Yes & Yes \\
\hline$p$-value for shock $k_{t}$ equality & 0.11 & 0.39 \\
\hline$p$-value for $s h o c k_{t-1}$ equality & N/A & 0.99 \\
\hline Observations & 5,493 & 4,980 \\
\hline R-squared (within) & 0.219 & 0.204 \\
\hline Number of Schools & 580 & 557 \\
\hline
\end{tabular}

${ }^{\dagger}$ This table shows the estimates of the model of the logarithm of endowment payout amounts when the effects of positive and negative shocks to the value of the endowment are allowed to differ. Column 1 shows the results with only contemporaneous shocks and column 2 includes lagged shocks as specified in equation (4). Endowment shocks and expected endowment variables are constructed using equation (1). "shock $k_{t}$ equality" refers to a test of the hypothesis that the coefficient on pos_endow_shock ${ }_{i t}$ equals that on neg_endow_shock ${ }_{i t}$. "shock $k_{t-1}$ equality" is defined analogously for lagged shocks in period $t$-1. Clustered and bootstrapped standard errors are in parentheses. Significance levels are indicated by: $* 10 \%, * * 5 \%, * * * 1 \%$ level. 


\section{Table A.1 ${ }^{\dagger}$}

Smooth Time Trends

\begin{tabular}{|c|c|c|}
\hline & \multicolumn{2}{|c|}{$\log$ (Payout Value) } \\
\hline & $(1)$ & (2) \\
\hline pos_endow_shock $k_{i t}$ & $\begin{array}{c}-0.189 \\
(0.131)\end{array}$ & $\begin{array}{c}-0.184 \\
(0.113)\end{array}$ \\
\hline neg_endow_shock $k_{i t}$ & $\begin{array}{l}-0.0643 \\
(0.103)\end{array}$ & $\begin{array}{l}-0.0801 \\
(0.119)\end{array}$ \\
\hline pos_endow_shock $_{i, t-1}$ & $\begin{array}{l}1.430 * * \\
(0.658)\end{array}$ & $\begin{array}{l}1.425^{*} \\
(0.741)\end{array}$ \\
\hline neg_endow_shock $k_{i, t-1}$ & $\begin{array}{c}1.585^{* *} \\
(0.701)\end{array}$ & $\begin{array}{c}1.597 * * \\
(0.760)\end{array}$ \\
\hline exp_endow $_{i t}$ & $\begin{array}{l}-0.664 \\
(0.693)\end{array}$ & $\begin{array}{l}-0.662 \\
(0.785)\end{array}$ \\
\hline exp_endow $_{i, t-1}$ & $\begin{array}{l}1.460 * * \\
(0.714)\end{array}$ & $\begin{array}{l}1.454^{*} \\
(0.800)\end{array}$ \\
\hline Year & $\begin{array}{c}0.0472^{* * *} \\
(0.00584)\end{array}$ & $\begin{array}{c}0.0560 \\
(0.0372)\end{array}$ \\
\hline Year*Year & & $\begin{array}{c}-0.000183 \\
(0.000823)\end{array}$ \\
\hline Constant & $\begin{array}{l}-0.573 \\
(1.801)\end{array}$ & $\begin{array}{l}-0.607 \\
(1.509)\end{array}$ \\
\hline University fixed effects & Yes & Yes \\
\hline Year fixed effects & No & No \\
\hline$p$-value for $\operatorname{shock}_{t}$ equality & 0.50 & 0.51 \\
\hline$p$-value for $\operatorname{shock}_{t-1}$ equality & 0.18 & 0.66 \\
\hline Observations & 4,980 & 4,980 \\
\hline R-squared (within) & 0.200 & 0.200 \\
\hline Number of Schools & 557 & 557 \\
\hline
\end{tabular}

${ }^{\dagger}$ This table shows the estimates of equation (4) when the time effects are replaced with smooth time trends. Column (1) includes a linear time trend and column (2) includes a quadratic time trend. Endowment shocks and expected endowment variables are constructed using equation (1). "shock $k_{t}$ equality" refers to a test of the hypothesis that the coefficient on pos_endow_shock $k_{i t}$ equals that on neg_endow_shock $k_{i t}$. "shock $k_{t-1}$ equality" is defined analogously for lagged shocks. Clustered and bootstrapped standard errors are in parentheses. Significance levels are indicated by: $* 10 \%, * * 5 \%, * * * 1 \%$ level. 
Table A. $2^{\dagger}$

Including Additional Lags of Shocks

\begin{tabular}{|c|c|}
\hline & $\log ($ Payout Value) \\
\hline pos_endow_shock $k_{i t}$ & $\begin{array}{l}-0.215 \\
(0.134)\end{array}$ \\
\hline neg_endow_shock $k_{i t}$ & $\begin{array}{l}-0.284 \\
(0.293)\end{array}$ \\
\hline pos_endow_shock $k_{i, t-1}$ & $\begin{array}{c}1.957 * * * \\
(0.690)\end{array}$ \\
\hline neg_endow_shock $k_{i, t-1}$ & $\begin{array}{c}2.575^{* * *} \\
(0.697)\end{array}$ \\
\hline pos_endow_shock $_{i, t-2}$ & $\begin{array}{l}-0.227 \\
(1.334)\end{array}$ \\
\hline neg_endow_shock $k_{i, t-2}$ & $\begin{array}{l}-0.293 \\
(1.341)\end{array}$ \\
\hline pos_endow_shock $_{i, t-3}$ & $\begin{array}{c}0.722 \\
(1.071)\end{array}$ \\
\hline 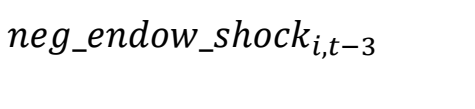 & $\begin{array}{c}0.686 \\
(1.048)\end{array}$ \\
\hline$e_{\text {exp_endow }}$ & $\begin{array}{c}-1.445^{* *} \\
(0.736)\end{array}$ \\
\hline exp_endow $w_{i, t-1}$ & $\begin{array}{c}2.366 \\
(1.713)\end{array}$ \\
\hline${\exp \_e n d o w_{i, t-2}}$ & $\begin{array}{l}-1.002 \\
(2.151)\end{array}$ \\
\hline exp_endow $w_{i, t-3}$ & $\begin{array}{c}0.810 \\
(1.172)\end{array}$ \\
\hline Constant & $\begin{array}{c}1.675 \\
(3.231)\end{array}$ \\
\hline $\begin{array}{l}p \text {-value for shock } k_{t} \text { equality } \\
p \text {-value for } \operatorname{shock}_{t-1} \text { equality }\end{array}$ & $\begin{array}{l}0.87 \\
0.21\end{array}$ \\
\hline $\begin{array}{l}\text { University fixed effects } \\
\text { Year fixed effects }\end{array}$ & $\begin{array}{l}\text { Yes } \\
\text { Yes }\end{array}$ \\
\hline $\begin{array}{l}\text { Observations } \\
\text { R-squared (within) } \\
\text { Number of Schools }\end{array}$ & $\begin{array}{c}4,045 \\
0.154 \\
508\end{array}$ \\
\hline
\end{tabular}

${ }^{\dagger}$ This table shows the estimates of the model of the logarithm of endowment payout amounts when second and third lags of endowment shocks are included. Clustered and bootstrapped standard errors are in parentheses. Significance levels are indicated by: $* 10 \%$, **5\%, ***1\% level. 


\section{Table A. $\mathbf{3}^{\dagger}$ \\ Estimates of BDKW's Model}

\begin{tabular}{lc}
\hline & Payout Rate \\
\hline Shock_Pos_BDKW & 0.00372 \\
& $(0.128)$ \\
Shock_Neg_BDKW & $0.355^{*}$ \\
& $(0.196)$ \\
Shock_Pos_BDKW $W_{i, t-1}$ & $-0.453^{* * *}$ \\
& $(.0787)$ \\
Shock_Neg_BDKW & $-0.718^{* * *}, 1$ \\
& $(0.227)$ \\
& $5.079^{* * *}$ \\
Constant & $(0.0780)$ \\
& \\
University fixed effects & Yes \\
Year fixed effects & Yes \\
p-value for shock $k_{t}$ equality & 0.24 \\
p-value for shock $k_{t-1}$ equality & 0.31 \\
Observations & 5,538 \\
R-squared (within) & 0.062 \\
Number of Schools & 606 \\
\hline
\end{tabular}

† This table shows the estimates when Brown, Dimmock, Kang and Weisbenner's (BDWK) model of payout rates is estimated using our data. Endowment shocks are constructed as the annual rate of return on the endowment multiplied by the ratio of startof-year endowment value to total university costs. "shock $k_{t}$ equality" refers to a test of the hypothesis that the coefficient on Shock_Pos_BDKW $W_{i t}$ equals that on Shock_Neg_BDKW $W_{i t}$. "shock st-1 $_{-}$equality" is defined analogously for lagged shocks. Clustered standard errors are in parentheses. Significance levels are indicated by: $* 10 \%$, $* * 5 \%$, ***1\% level. 